\title{
Estudo dos gêneros discursivos sob a perspectiva da Análise Dialógica do Discurso: percurso teórico e metodológico
}

\author{
Sueli Gedoz ${ }^{1}$
}

\section{Resumo}

A temática discutida neste trabalho refere-se à reflexão dos gêneros discursivos sob a perspectiva teórica da Análise Dialógica do Discurso (ADD). O texto apresenta os conceitos bakhtinianos que amparam a constituição da ADD, delineando o surgimento e o desenvolvimento dessa corrente de estudos, situando-a como uma perspectiva que busca encaminhamentos metodológicos para as discussões relacionadas à linguagem, ao discurso e ao enunciado. A pesquisa desenvolvida mostra uma possibilidade de relação entre teoria e prática, indicando como a proposta bakhtiniana pode ser conferida em um enunciado concreto, moldado em um gênero discursivo, utilizando-se, para isso, um texto do gênero cartaz. Os resultados verificados ratificam a necessidade de um olhar dialógico para as relações que se estabelecem nos elementos que configuram o gênero discursivo e apontam possibilidades de compreensão do texto conforme o percurso sugerido pelos estudos bakhtinianos, orientadores da ADD. Subsidiam o trabalho, as obras de Bakhtin/Volochinov (2004), Bakhtin (1976, 2000, 2002), Brait (2003, 2006) e Rodrigues (2001, 2005).

Palavras-chave: Bakhtin; Análise Dialógica do Discurso; Gêneros Discursivos.

\begin{abstract}
:
The theme discussed in this paper refers to the reflection of speech genres from de theoretical perspective of Dialogic Discourse Analysis. The text presents the Bakhtinian concepts that support de constitution of Dialogic Discourse Analysis, outlining the emergence and development of this current study, placing it as a perspective that seeks methodological referrals of this discussions related to language, speech and enunciation. The research conducted shows a possible relationship between theory and practice, indicating how the Bakhtinian proposition can be given in a statement concrete, molded into a speech genre, using for that, a text of poster genre. Verified results confirm the need for a dialogical look at the relationships established in the elements that make up the speech genre and link text comprehension possibilities as the route suggested by Bakhtin studies, guiding the Dialogic Discourse Analysis. Subsidize the work, studies of Bakhtin/Volochinov (2004), Bakhtin (1976, 2000, 2002), Brait (2003, 2006) and Rodrigues (2001, 2005).
\end{abstract}

Key-words: Bakhtin; Dialogic Discourse Analysis; discursive genres.

\footnotetext{
${ }^{1}$ Doutora em Letras. Professora da Secretaria de Estado da Educação do Paraná (SEED/PR) e da Faculdade de Ciências Sociais Aplicadas de Cascavel - UNIVEL - Cascavel/PR. Pesquisadora colaboradora do Projeto "Formação continuada para professores da educação básica nos anos iniciais: ações voltadas para a alfabetização em municípios com baixo IDEB na região oeste do Paraná" (UNIOESTE/CAPES/INEP). Contato: oi_sueli@ hotmail.com

Revista Leitura V.1 no 55 - jan/jun 2015 - Número temático: Estudos em perspectivas dialógicas. Estudo dos gêneros discursivos sob a perspectiva da Análise Dialógica do Discurso: percurso teórico e metodológico. Sueli Gedoz. - p. 145 - 162.
} 


\section{Introdução}

A perspectiva desenvolvida pela Análise Dialógica do Discurso tem se configurado como uma proposta que contribui para a compreensão dos pressupostos teóricos elaborados por Mikhail Bakhtin e seu círculo, acerca da concepção que toma a linguagem como forma de interação. A partir dos postulados bakhtinianos, as relações dialógicas passaram a ser consideradas como elementos essenciais na análise de qualquer texto que pertence a um gênero discursivo, fortalecendo, assim, o movimento que considera a língua não como um ato individual, mas como uma forma de interagir, de responder ao solicitado e de construir diálogos que promovem a constituição social e histórica de seus falantes. Considerando essa linha teórica, o presente trabalho, sugere uma reflexão acerca dos estudos bakhtinianos e da orientação teórico-metodológica denominada Análise Dialógica do Discurso (ADD de ora em diante) e apresenta uma análise, orientada pelo binômio teoria e prática, cujo intuito reside na proposta de operacionalizar os pressupostos do Círculo, tarefa inerente à ADD.

Para atender a esses propósitos, apontamos alguns aspectos que localizam o surgimento e o desenvolvimento da ADD, definindo-a, a partir dos estudos de Brait (2003, 2006) como uma orientação que teoriza e busca encaminhamentos metodológicos para as discussões relacionadas à linguagem, ao discurso e ao enunciado. Em seguida, direcionamos a atenção às contribuições teóricas do pensamento bakhtiniano, fazendo uma retomada conceitual que abrange acepções de enunciado, de gênero discursivo e as definições que caracterizam o método sociológico, proposto pelo pensador russo, para o estudo da língua. Na parte final das reflexões, estabelecemos um diálogo entre a teoria e a prática, propondo uma análise que abrange os termos apresentados e suas relações com os textos que circulam socialmente, moldados nos gêneros discursivos. Utilizando dos recursos da pesquisa documental, escolhemos um texto do gênero cartaz e sobre seus aspectos linguísticos e extralinguísticos desenvolvemos alguns apontamentos, aliando pressupostos teóricos à prática analítica de um enunciado. Os resultados dessa investigação revelam os possíveis encaminhamentos que sustentam a ADD no campo dos estudos linguísticos e sua articulação aos estudos bakhtinianos.

\section{Análise Dialógica do Discurso: breve contextualização}


O conjunto das obras produzidas por Mikhail Bakhtin, Pavel Medvedev e Valentin Volochinov, bem como outros pensadores do grupo conhecido como Círculo de Bakhtin, sustentam o surgimento e o desenvolvimento da orientação teóricometodológica denominada Análise Dialógica do Discurso (ADD). Nas palavras de Brait (2003), essa corrente caracteriza-se como:

[...] um conjunto de procedimentos analíticos, um arcabouço teórico que, embora não formando um corpo acabado de conceitos e formas de aplicação, está articulado no conjunto das obras de Mikhail Bakhtin e seu círculo, independentemente da discussão a respeito da autoria individual de cada trabalho (BRAIT, 2003, p. 126).

A autora informa que na teorização elaborada pelo Círculo, há possíveis caminhos para se examinar a organização de diferentes discursos, o que contribui significativamente para uma nova perspectiva a respeito da linguagem humana. Considerando esse princípio, explica quais são os propósitos da ADD:

Sem querer (e sem poder) estabelecer uma definição fechada do que seria essa análise/teoria dialógica do discurso, uma vez que o fechamento significaria uma contradição em relação aos termos que a postulam, é possível explicar seu embasamento constitutivo, ou seja, a indissolúvel relação existente entre língua, linguagens, história e sujeitos que instaura os estudos da linguagem como lugares de produção de conhecimento de forma comprometida, responsável, e não apenas como procedimento submetido a teorias e metodologias dominantes em determinadas épocas. (BRAIT, 2006, p. 10).

É nítida a asseveração sobre a impossibilidade de criar uma metodologia de análise rígida na concepção bakhtiniana. O que ocorre para Brait (2003) é a informação de que Bakhtin não formalizou uma teoria para a análise do discurso, mas deixou apontamentos que sugerem encaminhamentos teóricos e metodológicos nessa acepção. É o que se verifica nos primeiros escritos do autor, datados da década de 1920:

Intitulamos este capítulo "O discurso em Dostoiévski" porque temos em vista o discurso, ou seja, a língua em sua integridade concreta e viva e não a língua como objeto específico da linguística, obtido por meio de uma abstração absolutamente legítima e necessária de alguns aspectos da vida concreta do discurso. Mas são justamente esses aspectos, abstraídos pela linguística, os que têm importância primordial para os nossos fins. Por este motivo as nossas análises subsequentes não são linguísticas no sentido rigoroso do termo. Podem ser situadas na metalinguística, subentendendo- a como um 
estudo - ainda não-constituído em disciplinas particulares definidas daqueles aspectos da vida do discurso que ultrapassam - de modo absolutamente legítimo - os limites da linguística. (BAKHTIN, 2002, p.181)

Nesse trecho da obra, Bakhtin reporta-se ao discurso socialmente produzido e compreendido a partir do viés da interação. A noção de interação nos remete à crítica bakhtiniana em relação ao caráter monológico da língua e ao discurso tomado de forma isolada. Para o autor, "[...] o discurso verbal em si, tomado isoladamente como um fenômeno puramente linguístico, não pode, naturalmente, ser verdadeiro ou falso, ousado ou tímido" (BAKHTIN, 1976, p. 5). Ou seja, o pensador russo se propõe a estudar o discurso a partir de sua imersão numa situação de interação, que requer elementos extralinguísticos, verificados na comunicação dialógica entre os sujeitos.

Na vida, o discurso verbal é claramente não autossuficiente. Ele nasce de uma situação pragmática extratextual e mantém conexão mais próxima possível com esta situação. Além disso, tal discurso é diretamente vinculado à vida em si e não pode ser divorciado dela sem perder sua significação (BAKHTIN, 1976, p. 4).

A interpretação desenvolvida por Brait (2006) sobre os aspectos linguísticos e extralinguísticos postulados por Bakhtin (1976, 2000) e Bakhtin/Volochinov (2004) evidencia que a linguística sistêmica não deve ser excluída dos estudos do discurso. Para Brait (2006), a ADD deve aproveitar os aspectos que compõem a materialidade linguística, internos no discurso, assim como considerar, dado o caráter dialógico da linguagem, os fatores extralinguísticos que caracterizam a enunciação.

O enfrentamento bakhtiniano da linguagem leva em conta, portanto, as particularidades discursivas que apontam para contextos mais amplos, para um extralinguístico aí incluído o trabalho metodológico, analítico e interpretativo com textos/discursos se dá [...] herdando da Linguística a possibilidade de esmiuçar campos semânticos, descrever e analisar micro e macroorganizações sintáticas, reconhecer, recuperar e interpretar marcas e articulações enunciativas que caracterizam o(s) discurso(s) e indiciam sua heterogeneidade constitutiva, assim como a dos sujeitos aí instalados (BRAIT, 2006, p. 13).

Considerar a linguagem nessa perspectiva pressupõe compreendê-la numa abordagem dialógica, socialmente constituída, materializada em diferentes discursos. 
Nas palavras de Bakhtin:

A linguagem só vive na comunicação dialógica daqueles que a usam. É precisamente essa comunicação dialógica que constitui o verdadeiro campo da vida da linguagem. Toda vida da linguagem, qualquer que seja seu campo de emprego, está impregnada de relações dialógicas (BAKHTIN, 2002, p. 209).

A linguagem é um fator que constitui o homem, uma vez que exerce função social e comunicativa, o que possibilita um contato com o mundo. Ao proporem esse encaminhamento para análise do discurso, definido por pesquisadores brasileiros como Análise Dialógica do Discurso, Bakhtin/Volochinov (2004) ${ }^{2}$ e Bakhtin (2000) ${ }^{3}$ não negam a estrutura da língua, mas afirmam que ela deve ser estudada e compreendida a partir de enunciados concretos. Os autores questionam a corrente que considera a linguagem como sistema abstrato de formas (objetivismo abstrato) e a que se refere à enunciação monológica isolada (subjetivismo idealista), explicando que "[...] na prática viva da língua, a consciência linguística do locutor e do receptor nada tem a ver com o sistema abstrato de formas normativas, mas apenas com a linguagem no sentido de conjunto dos contextos possíveis de uso de cada forma particular" (BAKHTIN/ VOLOCHINOV, 2004, p. 95).

Nesse sentido, a comunicação é vista como um processo interativo, que abarca muito mais do que a simples transmissão de informações. A linguagem é uma forma de interação social. E, nesse contexto, o enunciado só é compreendido a partir de uma interação ativa entre os sujeitos e, portanto, toda enunciação é socialmente dirigida. É na atividade de interação verbal, por meio da consideração dos aspectos extralinguísticos, que a palavra ganha significado, dependendo do contexto em que se insere. Assim, a interação verbal constitui-se como uma categoria básica para Bakhtin/Volochinov (2004), sendo considerada a realidade fundamental da língua, aspecto imprescindível nos estudos da ADD.

A verdadeira substância da língua não é constituída por um sistema abstrato de formas linguísticas nem pela enunciação monológica isolada, nem pelo ato fisiológico de sua produção, mas pelo fenômeno social da interação verbal, realizada através da enunciação ou das enunciações. A interação verbal constitui assim a realidade

\footnotetext{
${ }^{2}$ A publicação inicial dessa obra data de 1979.

${ }^{3}$ A publicação inicial dessa obra data de 1929.
} 
fundamental da língua (BAKHTIN/VOLOCHINOV, 2004, p. 123, grifos do autor).

Os autores também defendem que a linguagem é um ato social, de natureza socioideológica e tudo "[...] que é ideológico possui um significado e remete a algo situado fora de si mesmo" (BAKHTIN/VOLOCHINOV, 2004, p. 31, grifos do autor). Tal apontamento mais uma vez remete ao extralinguístico, aspecto da linguagem que permite o estabelecimento de relações dialógicas. Essas relações são estabelecidas a partir das esferas discursivas e dos eventos nelas inseridos. Para Bakhtin (2000), “A relação dialógica pressupõe uma língua, mas não existe no sistema da língua. Não pode estabelecer-se entre os elementos da língua" (BAKHTIN, 2000, p. 345), ou seja, as relações dialógicas estão presentes na interação e na materialização extralinguística do discurso.

Dessa forma, as relações dialógicas direcionam o discurso e constituem os enunciados, definidos por Bakhtin (2000) como unidades reais de comunicação discursiva. Os conceitos relacionados à enunciação e ao enunciado são apresentados na seção seguinte deste estudo.

\section{O enunciado}

Outro estudo desenvolvido por Bakhtin e seu círculo remete à materialização do discurso na forma de um enunciado, definido como “[...] a unidade real da comunicação verbal" (BAKHTIN, 2000, p. 293).

Se considerarmos os enunciados como formas utilizadas pelas pessoas para interagirem, podemos dizer que representam todo o repertório do que ouvimos e reproduzimos na comunicação discursiva efetiva que realizamos. Quando produzimos um enunciado, estamos fazendo uso de uma linguagem social, pertencente a um grupo social particular de falantes. Bakhtin (2000) aponta que "[...] a utilização da língua efetua-se em forma de enunciados (orais e escritos), concretos e únicos, que emanam dos integrantes duma ou doutra esfera da atividade humana" (BAKHTIN, 2000, p. 280). A esse respeito, Rodrigues (2001) ratifica:

Se a formação do enunciado não pode ser vista isoladamente, mas na sua relação dinâmica com os outros enunciados, pertencentes aos outros participantes da comunicação discursiva, da mesma forma, ele 
não pode ser separado da situação social. Não se pode compreender o enunciado sem correlacioná-lo com a sua situação social, pois o discurso, como fenômeno de comunicação social, é determinado pelas relações sociais que o suscitaram (RODRIGUES, 2001, p. 20).

Compreendemos, portanto, que ao proferirmos um enunciado, consideramos sempre o contexto da enunciação, ou seja, enuncia-se sempre para alguém, de um determinado lugar ou de uma determinada posição sócio histórica. Por isso, no estudo da enunciação é necessário considerar o contexto de produção dos enunciados: onde, quem, quando, para quem e por que foi produzido, além de todo o conhecimento sóciohistórico-ideológico que envolve os interlocutores. Nesse caso, sua compreensão está muito além da decodificação porque pressupõe sua relação com os participantes da situação.

Com efeito, a enunciação é o produto da interação de dois indivíduos socialmente organizados e, mesmo que não haja um interlocutor real, este pode ser substituído pelo representante médio do grupo social ao qual pertence o locutor. A palavra dirige-se a um interlocutor: ela é função da pessoa desse interlocutor: variará se se tratar de uma pessoa do mesmo grupo social ou não, se esta for inferior ou superior na hierarquia social, se estiver ligada ao locutor por laços sociais mais ou menos estreitos (pai, mãe, marido, etc.) (BAKHTIN/VOLOCHINOV, 2004, p. 112, grifos do autor).

Logo, o enunciado constitui-se na relação entre os sujeitos e, por um lado, pode ser tomado como um ato irrepetível, um evento único no processo de interação que cada vez que é enunciado, apresenta-se como um novo enunciado. (BAKHTIN/VOLOCHINOV, 2004); por outro, é um evento dialógico, pois oferece uma resposta a algo já dito e aguarda uma nova resposta. É o princípio da atitude responsiva do falante/locutor/enunciador:

As fronteiras do enunciado concreto, compreendido como uma unidade da comunicação verbal, são determinadas pela alternância dos sujeitos falantes, ou seja, pela alternância dos locutores [...] O locutor termina seu enunciado para passar a palavra ao outro ou para dar lugar à compreensão responsiva ativa do outro. O enunciado não é uma unidade convencional, mas uma unidade real, estritamente delimitada pela alternância dos sujeitos falantes, e que termina por uma transferência da palavra para o outro [...] (BAKHTIN, 2000, p. 293-294, grifos do autor) 
Assim sendo, o enunciado é marcado por relações dialógicas que o constroem, ou seja, é formado a partir de uma constituição linguística interna, por elementos extralinguísticos que o definem e pelas contribuições do discurso do outro. Além disso, concorrem também na construção do enunciado. Para Bakhtin (2000), “[...] cada esfera de utilização da língua elabora seus tipos relativamente estáveis de enunciados" (BAKHTIN, 2000, p. 279, grifos do autor). Segundo o autor, o ser humano, em quaisquer de suas atividades, vai servir-se da língua e a partir do interesse, intencionalidade e finalidade específicos de cada atividade, os enunciados linguísticos se concretizarão de maneiras diversas. A essas formas de incidência dos enunciados, Bakhtin (2000) denomina de gêneros discursivos, tema que abordamos na parte seguinte deste estudo.

\section{Os gêneros discursivos}

Considerando que “[...] cada esfera de utilização da língua elabora seus tipos relativamente estáveis de enunciados, sendo isso que denominamos de gêneros do discurso" (BAKHTIN, 2000, p. 279, grifos do autor), podemos dizer que o ser humano, em quaisquer de suas atividades de interação, vai se servir da linguagem e, a partir de interesses, intencionalidades e finalidades específicos de cada ação, produzirá enunciados que se organizarão de maneiras diversas. A essas diferentes formas de incidência dos enunciados, o autor denomina gêneros do discurso. Sendo caracterizados como modelos de enunciados, os gêneros discursivos são textos orais e escritos, concretos e únicos, "[...] que emanam dos integrantes duma ou doutra esfera da atividade humana" (BAKHTIN, 2000, p. 279), diferenciando-se uns dos outros devido às características, às peculiaridades e às necessidades de cada esfera social, fazendo parte, assim, de sua cultura. O filósofo russo afirma:

A riqueza e a variedade dos gêneros do discurso são infinitas, pois a variedade virtual da atividade humana é inesgotável, e cada esfera dessa atividade comporta um repertório de gêneros do discurso que vai diferenciando-se e ampliando-se à medida que a própria esfera se desenvolve e fica mais complexa (BAKHTIN, 2000, p. 279).

De acordo com Rodrigues (2005), ao apresentarmos a noção de gêneros do discurso na perspectiva do círculo de Bakhtin, não é possível “[...] dissociá-la das 
noções de interação verbal, comunicação discursiva, língua, discurso, texto, enunciado, e atividade humana, pois somente na relação com esses conceitos pode-se apreender, sem reduzir, a noção de gênero" (RODRIGUES, 2005, p. 154, grifos da autora). Retratando o vínculo existente entre gênero e enunciado e, recorrendo ao pensamento bakhtiniano, a autora informa que os gêneros discursivos:

[...] são 'impessoais', pois não são os próprios enunciados, individuais e irrepetíveis. [...] apesar da imensa variedade e heterogeneidade dos gêneros do discurso, que os diferenciam uns dos outros, reflexo das possibilidades inesgotáveis da atividade humana, das condições e das diferentes funções das esferas sociais, todos possuem um traço que os une, que é a sua natureza verbal comum (RODRIGUES, 2001, p. 42).

De tal maneira o fato de serem considerados tipos de enunciados relativamente estáveis, faz com que os gêneros compartilhem das propriedades sócio-discursivas dos enunciados. Entretanto, no que concerne às suas particularidades e ao aspecto da interação verbal, os gêneros são "[...] formas típicas e normativas do ponto de vista temático, estilístico e composicional para a construção do enunciado total" (RODRIGUES, 2001, p. 42, grifos da autora).

Ao considerar ponto de vista temático, estilístico e composicional de cada gênero, a interpretação realizada por Rodrigues (2001) refere-se ao método sociológico proposto por Bakhtin (2000) e Bakhtin/Volochinov (2004), o qual discorremos na parte seção seguinte.

\section{O método sociológico e sua contribuição para a ADD}

Reportando-se ao fenômeno social da interação verbal, realizada por meio de enunciados e enunciações, Bakhtin/Volochinov (2004) reforça o caráter dialógico da língua, mostrando que é por meio dela que produzimos enunciados concretos que pertencem a diferentes. Dessa forma, os gêneros organizam nossa fala e possibilitam a interação verbal. De acordo com Bakhtin (2000):

Os gêneros do discurso organizam nossa fala da mesma maneira que a organizam as formas gramaticais (sintáticas). Aprendemos a moldar nossa fala às formas do gênero e, ao ouvir a fala do outro, sabemos de imediato, bem nas primeiras palavras, pressentir-lhe o gênero, adivinhar-lhe o volume (a extensão aproximada de todo o discurso), a dada estrutura composicional, prever-lhe o fim, ou seja, desde o início 
somos sensíveis ao todo discursivo que, em seguida, no processo de fala, evidenciará suas diferenciações (BAKHTIN, 2000, p. 302).

Os postulados de Bakhtin e seu círculo reportam-se ao que o autor propôs como encaminhamento para a investigação das particularidades de cada gênero discursivo, sendo expresso inicialmente em Marxismo $e$ Filosofia da Linguagem (BAKHTIN/VOLOCHINOV, 2004) como uma ordem metodológica para o estudo da língua:

1. As formas e os tipos de interação verbal em ligação com as condições concretas em que se realiza.

2. As formas das distintas enunciações, dos atos de fala isolados, em ligação estreita com a interação de que constituem os elementos, isto é, as categorias de atos de fala na vida e na criação ideológica que se prestam a uma determinação pela interação verbal.

3. A partir daí, exame das formas da língua na sua interpretação linguística habitual (BAKHTIN/VOLOCHINOV, 2004, p. 124).

Essa orientação é retomada, posteriormente, por Bakhtin, na obra Estética da Criação Verbal, quando aponta três elementos para o estudo do gênero a que pertence determinado enunciado: conteúdo temático, estilo e construção composicional .

O enunciado reflete as condições específicas e as finalidades de cada uma dessas esferas, não só por seu conteúdo (temático) e por seu estilo verbal, ou seja, pela seleção operada nos recursos da língua recursos lexicais, fraseológicos e gramaticais -, mas também, e sobretudo, por sua construção composicional. Esses três elementos (conteúdo temático, estilo e construção composicional) fundem-se indissoluvelmente no todo do enunciado e todos são marcados pela especificidade de uma esfera de comunicação (BAKHTIN, 2000, p. 279 , grifos nossos).

As recomendações de Bakhtin (2000) instauram uma ordem/organização/roteiro para um processo investigativo do discurso organizado no gênero e proporcionam condições para um olhar dialógico a ser estendido ao texto. Partindo da proposta bakhtiniana, a ADD ratifica a necessidade e avaliarmos o discurso e a linguagem considerando seus aspectos históricos, sociais e linguísticos.

Na tentativa de demonstrar um estudo pautado nesse método, em consonância com a $\mathrm{ADD}$, escolhemos um texto que pertence a determinado gênero discursivo e desenvolvemos uma análise considerando o encaminhamento bakhtinano compreendido pela ADD. As reflexões aplicam-se a um texto do gênero cartaz. O cartaz em questão 
não apresenta título definido, por isso, nossa referência a ele será "Cartaz de divulgação da vacina contra a gripe", que apresentamos na sequência:

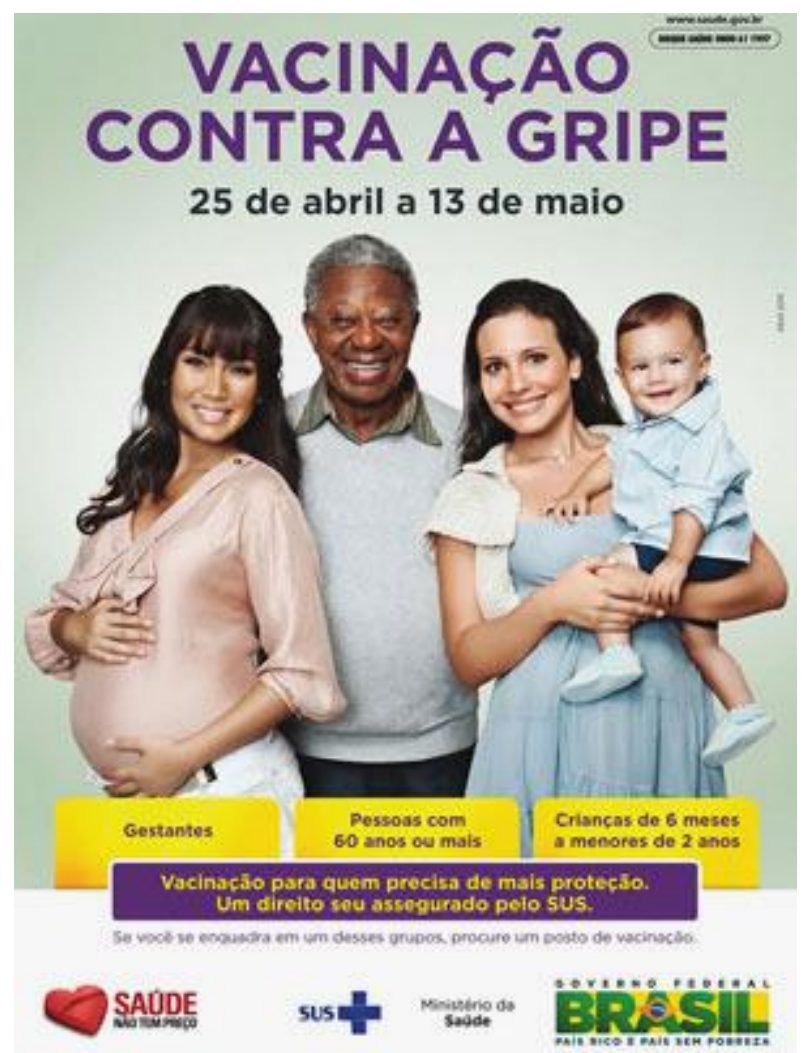

Fonte: <http://portalsaude.saude.gov.br/portalsaude/index.html>

Observamos que trata-se de um texto com função social definida, um enunciado concreto produzido a partir de uma intenção comunicativa, de um querer-dizer do locutor, o que revela uma situação social de produção. A materialidade linguística é observada no discurso que organiza o texto.

Textos desse gênero, de acordo com Cereja e Magalhães (2005), têm a finalidade de informar as pessoas, sensibilizá-las, convencê-las ou conscientizá-las sobre determinado assunto. Além disso, também apresentam a função social de argumentar, promover, convidar, instruir, esclarecer, reivindicar, solicitar, divulgar entre outras. Os cartazes que se assemelham ao texto em estudo, geralmente são afixados em lugares públicos, objetivando divulgar uma campanha. A linguagem é verbal e não verbal, incluindo textos verbais curtos e simples. No "Cartaz de divulgação da vacina contra a gripe" podemos dizer que prevalecem as funções de informar, argumentar e convencer. Para isso, é evidente uma recorrência a recursos da 
linguagem verbal e não verbal com o intuito de chamar a atenção do interlocutor para o querer-dizer do locutor. Na visão de Morais (2005):

Especificamente os cartazes de campanhas publicitárias preventivas relacionadas ao Ministério da Saúde do Governo Federal têm como objetivo orientar a população para cuidados que se devem ter em relação à saúde e convencer os leitores de que é necessária uma mudança de pensamento e de atitudes para que se tenha uma melhor qualidade de vida (MORAIS, 2005, p. 1)

Reportando-nos ao método sociológico proposto por Bakhtin (2000), situamos o conteúdo temático do texto em questão. Ao analisarmos esse aspecto, deparamo-nos com apontamentos relacionados à: objetivo com que o locutor produziu determinado texto e para qual interlocutor(es) se destina, recurso/veículo utilizado para sua divulgação/socialização, suporte em que o texto foi veiculado e época (data/período) em que foi produzido, retomando o contexto sócio-histórico-ideológico que, direta ou indiretamente, interfere no tema. Bakhtin/Volochinov (2004) informam que "[...] o tema é determinado não só pelas formas linguísticas que entram na composição (as palavras, as formas morfológicas ou sintáticas, os sons, as entoações), mas é igualmente determinado pelos elementos não-verbais da situação" (BAKHTIN/VOLOCHINOV, 2004, p. 128)

Recuperando o contexto para melhor definir o tema, vemos que o texto em análise foi produzido pela esfera publicitária por tratar-se de um cartaz, cujo foco é a divulgação de campanha de vacinação contra a gripe. A circulação do texto estende-se a diversas esferas de comunicação, pois se reporta a todos os ambientes em que o cartaz será divulgado. Os suportes de textos desse gênero geralmente são murais ou paredes, espaços nos quais os cartazes são afixados. No caso do cartaz em questão, trata-se de um texto elaborado com o propósito de estabelecer a interação entre o locutor e o interlocutor, inicialmente informando acerca de uma campanha preventiva, argumentando em favor dos direitos das pessoas atingidas pela campanha e, na parte final, convocando o interlocutor para participar da campanha divulgada.

O conteúdo temático está relacionado, portanto, à vacinação de gestantes, idosos e crianças de 2 meses a 6 anos de idade contra a gripe H1N1, ou influenza A, provocada pelo vírus H1N1 da influenza do tipo A. Trata-se de um tema conhecido pelo interlocutor, dada a repercussão que teve no ano de 2009, quando a referida doença provocou preocupações em toda a população brasileira, bem como nos órgãos de saúde 
pública e particular. O texto foi produzido com o objetivo de informar sobre a data de realização da campanha, argumentar em favor do direito concedido ao público que será atingido e apresentar os articuladores dessa prevenção, no caso, o governo federal e as organizações a ele subordinadas.

O cartaz em questão foi produzido nos meses iniciais do ano de 2011 e sua divulgação aconteceu no final do mês de abril/2011. Esse período histórico é significativo para a produção desse texto. A gripe H1N1 ou influenza A chegou ao Brasil no ano de 2009 e, em março de 2010, o Ministério da Saúde lançou uma campanha de vacinação contra essa doença. Entretanto, à época, surgiram nas mídias eletrônicas, diversas informações não comprovadas cientificamente, colocando em dúvida a eficácia da vacina e/ou conspirando contra seus benefícios para a saúde da população. Sites e $e$-mails diversos apresentavam informações contrárias à campanha de vacinação então instalada, o que fez com que muitas pessoas optassem pela não adesão à vacina contra a gripe $\mathrm{H} 1 \mathrm{~N} 1$ ou influenza $\mathrm{A}$.

Diante dessa situação vivenciada em 2010, o governo federal usou estratégias diferenciadas para a campanha de 2011, sendo uma delas a elaboração do cartaz em análise, que conta com elementos não verbais significativos para o convencimento da população pertencente aos grupos que devem ser afetados pela vacina. Esse dado confirma o que Bakhtin/Volochinov (2004) propõe como conteúdo temático de um texto: "O tema da enunciação é concreto, tão concreto como o instante histórico ao qual ela pertence" (BAKHTIN/VOLOCHINOV, 2004, p. 129). Caso não estivesse relacionado a uma questão socialmente construída, ou seja, à falta de confiança da população na vacina, o cartaz em análise possivelmente não traria a imagem de pessoas que circulam na mídia. $\mathrm{O}$ apelo à imagem dos artistas é o elemento extralinguístico que marca as relações dialógicas presentes nesse enunciado. Tais elementos oferecem suas contribuições ao discurso à medida que agem como estratégias de convencimento do interlocutor. A imagem dos artistas: Daniele Suzuki, grávida de 7 meses, Juliana Knust, com o filho Mateus em seu colo e Milton Gonçalves, com 77 anos de idade, representando o grupo do idosos que devem ser vacinados, transmite a ideia de que todas as pessoas pertencentes a esses grupos serão vacinadas, inclusive os artistas. Dessa forma, o papel social desempenhado pelo contexto de produção tem influência relevante sobre o conteúdo temático veiculado no texto. As características relativamente estáveis (BAKHTIN, 2000) desse gênero, articuladas ao conteúdo temático do cartaz em análise, permitem as considerações apresentadas. 
Em se tratando de estrutura composicional, conforme apontado, os textos do gênero cartaz geralmente são produzidos na esfera publicitária. Trata-se de textos curtos, que utilizam da linguagem verbal e não verbal, promovendo, nos aspectos não verbais, relações dialógicas expressas nos seus elementos extralinguísticos (BAKHTIN, 2000).

Essa composição pode ser verificada nas informações presentes no texto:

Informações pontuais sobre a campanha (tipo de

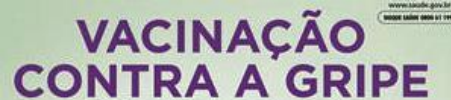

25 de abril a 13 de maio campanha e data de realização). Recursos da

$\longrightarrow$ linguagem verbal (palavras com letras em caixa alta, na parte superior central do cartaz) utilizados para chamar a atenção do leitor,

Recursos da linguagem não verbal: imagem de artistas que correspondem às pessoas que devem

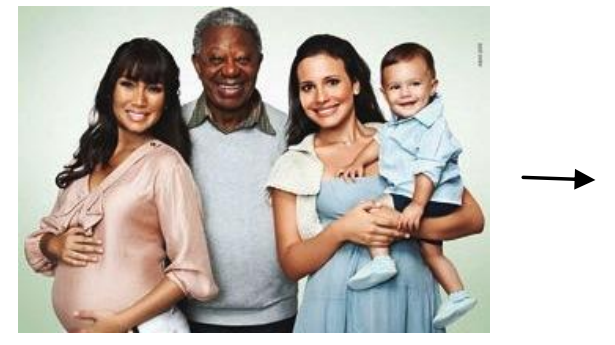
ser atingidas pela campanha. Recurso argumentativo em favor da ideia lançada no cartaz, chamando a atenção do interlocutor.

Recursos da linguagem verbal utilizados para informar acerca dos grupos atingidos pela campanha e convencer/convocar o interlocutor para a vacinação.

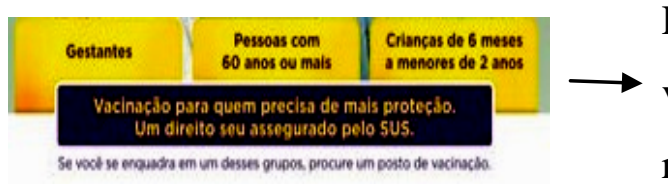

Elementos que utilizam linguagem verbal e não verbal com o intuito de informar sobre os responsáveis pela realização/articulação da campanha. 
A parte inicial é informativa, seguida de uma imagem de teor argumentativo. A parte final destina-se novamente a informações, apresentando um aspecto indispensável ao conteúdo temático do gênero cartaz, já que não é possível divulgar uma campanha sem apresentar informações pontuais sobre a sua realização. Entretanto, uma das partes fundamentais do gênero, e evidente no texto em análise, é a injunção, cuja composição utiliza-se de verbos no modo imperativo. No fragmento "Se você se enquadra em um desses grupos, procure um posto de vacinação" o verbo "procure" indica uma solicitação ao interlocutor, que pode ser entendida como um convite ou até mesmo uma convocação.

Essa estrutura na composição dos aspectos linguísticos e extralinguísticos predominantes no cartaz, a disposição de cada fragmento no espaço do texto (esquerda, direita, acima, abaixo), bem como a imagem de artistas simbolizando o grupo que deve ser atingido pela campanha e, ao mesmo tempo, excluindo as pessoas que não se enquadram nesses grupos, fazem com que o gênero cumpra sua função social e promova uma interação entre seus produtores e seus interlocutores.

O terceiro elemento a ser verificado no percurso metodológico exposto por Bakhtin (2000) refere-se ao estilo do gênero:

O estilo é indissociavelmente vinculado a unidades temáticas determinadas e, o que é particularmente importante, a unidades composicionais: tipo de estruturação e de conclusão de um todo, tipo de relação entre um locutor e os outros parceiros da comunicação verbal (BAKHTIN, 2000, p. 284).

Para Bakhtin (2000) todo enunciado é individual e por isso pode refletir o estilo próprio do gênero, da esfera social e do autor. No caso do texto analisado, há aspectos próprios da esfera (publicitária) e do gênero (cartaz). Entretanto, comunga também com a individualidade de $\operatorname{seu}(\mathrm{s})$ produtor(es), apresentando, nesse caso, a intenção do governo federal na divulgação de uma campanha de vacinação que atinja grupos específicos de cidadãos. Isso é evidenciado pela imagem dos artistas, destacada no plano central do cartaz e pelas informações imediatamente apresentadas abaixo da imagem de cada artista. O texto explora aspectos verbais e não verbais que se complementam para expressar as informações que o compõe. Esse recurso, que pode ser marcado como um dos definidores do estilo do gênero, insere-se no que Koch e Travaglia (2000) definem como fatores de contextualização, sendo "[...] aqueles que 
'ancoram' o texto em uma situação comunicativa determinada" (KOCH; TRAVAGLIA, 2000, p. 67). Ou seja, são os elementos que auxiliam o interlocutor a decodificar e compreender a função social do texto. Os autores informam que fatores gráficos, o título do texto e o nome do autor são elementos importantes que permitem ao leitor interpretar melhor um texto e até mesmo fazer previsões sobre sua forma e conteúdo $(\mathrm{KOCH}$; TRAVAGLIA, 2000). No caso do gênero em estudo, os fatores gráficos auxiliam para sua contextualização, uma vez que "Entre os fatores gráficos, temos: disposição na página, ilustração, fotos [...] que contribuem para a interpretação do texto" (KOCH; TRAVAGLIA, 2000, p. 65).

Outro aspecto do estilo do texto que merece atenção refere-se ao uso do verbo no modo imperativo (verbo "procure"). Conforme comentado, é próprio desse gênero a utilização de verbos nesse modo. Para que os textos desse gênero estabeleçam coerência comunicativa, necessitam coagir o interlocutor a realizar uma determinada ação, daí a importância da utilização de verbos que induzem atitudes. A situação comunicativa requer escolhas lexicais próprias para o gênero a fim de contribuir para o sucesso de sua função social.

\section{Considerações finais}

$\mathrm{O}$ texto apresentado partiu de um propósito investigativo intrínseco à $\mathrm{ADD}$, ou seja, estabelecer uma reflexão acerca de alguns conceitos produzidos pelo círculo bakhtiniano, verificando o modo como tais conceitos se configuram em um texto pertencente a um determinado gênero discursivo. Trata-se de uma investigação analítica que conjuga pressupostos teóricos e orientação metodológica com vistas à compreensão do caráter dialógico da linguagem em situações reais de uso. Acreditamos que as discussões polarizam alguns dos conceitos fundamentais propostos nas investigações de Bakhtin e seu círculo, os quais ampliam nossas considerações em relação aos estudos da língua e dos gêneros discursivos.

A análise documental empreendida ao gênero cartaz, situando o conteúdo temático, a estrutura composicional e o estilo dos textos desse gênero e, especificamente, do texto selecionado "Cartaz de divulgação da vacina contra a gripe" expõe o contexto de produção do enunciado, o querer dizer do interlocutor e as possibilidades responsivas do interlocutor, além de averiguar as relações dialógicas decorrentes dos aspectos não verbais presentes no texto. 
Assim sendo, entendemos que os propósitos, inicialmente estabelecidos, foram contemplados na análise realizada, e abrem caminho para outras investigações que tenham como escopo a averiguação da teoria bakhtiniana, utilizando-se, para isso, postulados da $\mathrm{ADD}$, já que esta pode ser compreendida como uma orientação dos aspectos metodológicos dos pressupostos desenvolvidos pelo círculo de Bakhtin.

\section{Referências}

BAKHTIN, M. (VOLOCHINOV). Marxismo e filosofia da linguagem. 11. ed. São Paulo: Hucitec, 2004.

. Problemas da poética de Dostoiévski. 3. ed. Rio de Janeiro: Forense Universitária (original russo 1929, modificado em 1963), 2002.

. Discurso na vida e na arte: sobre a poética sociológica. Trad. de Carlos Alberto Faraco e Cristóvão Tezza da edição inglesa de TITUNIK, I. R. "Discourse in life and discourse in art - concerning sociological poetics". In: VOLOSHINOV, V. N. Freudism. New York: Academic Press (originalmente publicado em 1926), 1976.

Estética da criação verbal. 3. ed. São Paulo: Martins Fontes, 2000.

BRAIT, B. Análise e Teoria do Discurso. In: BRAIT, B. Bakhtin: Outros Conceitoschave. São Paulo: Contexto, 2006. p. 9-31.

Interação, gênero e estilo. In: PETRI, D. (Org.) Interação na fala e na escrita. São Paulo: Humanitas. 2003, p. 125-157.

CEREJA, W. R.; MAGALHÃES, T. C. Texto e Interação: uma proposta de produção textual a partir dos gêneros e projetos. São Paulo: Atual, 2005.

KOCH, I. G. V.; TRAVAGLIA, L. C. A coerência textual. 10. ed. São Paulo: Contexto, 2000.

MORAIS, M. B. A polifonia como estratégia argumentativa: uma análise do gênero cartaz de campanha preventiva do governo federal. In: REUNIÃO ANUAL DA SBPC, 57, Fortaleza, CE. Anais... Fortaleza, CE: 2005, p. 1-12. Disponível em: <http://www.sbpcnet.org.br/livro/57ra/programas/senior/470.html>. Acesso em: 20 nov. 2013.

RODRIGUES, R. H. Os gêneros do discurso na perspectiva dialógica da linguagem: a abordagem do círculo de Bakhtin. In: MEURER, José Luiz; BONINI, Adair; MOTTAROTH, Désirée. (org.). Gêneros: teorias, métodos, debates. São Paulo: Parábola, 2005. p. 152-183.

A constituição e o funcionamento do gênero jornalístico artigo: cronotopo e dialogismo. São Paulo, 2001. 347p. Tese (Doutorado em Linguística Aplicada e Estudos 
da Linguagem). Programa de Estudos Pós-graduados em Linguística Aplicada e Estudos da Linguagem. Pontifícia Universidade Católica. 